\title{
Six-Minute Walk Test in Patients with Rheumatoid Arthritis
}

\author{
Sandor Balsamo 1,2,3,4, Ana Paula Monteiro Gomides 1,2,5*, Licia Maria Henrique da Mota1,2,5, \\ Frederico Santos de Santana, ${ }^{1,2,3}$, Raphaela Franco Miranda4, Talita Yokoy, ${ }^{1,2,5}$, \\ Luciana Muniz ${ }^{1,2,5}$, Leopoldo Luiz Santos-Neto ${ }^{1,2,5}$ \\ ${ }^{1}$ Universidade de Brasília (UnB), Brasília, Brazil \\ ${ }^{2}$ Laboratório de Aptidão Física e Reumatologia do Hospital Universitário de Brasília (LAR/HUB), Brasília, Brazil \\ ${ }^{3}$ Grupo de Estudo e Pesquisa em Exercício de Força e Saúde (GEPEEFS), Brasília, Brazil \\ ${ }^{4}$ Curso Superior de Educação Física, Centro Universitário UNIEURO, Brasília, Brazil \\ ${ }^{5}$ Ambulatório de Reumatologia, Hospital Universitário de Brasília (HUB), Brasília, Brazil \\ Email: *anapmgomides@gmail.com
}

How to cite this paper: Balsamo, S., Gomides, A.P.M., da Mota, L.M.H., de Santana, F.S., Miranda, R.F., Yokoy, T., Muniz, L. and Santos-Neto, L.L. (2019) Six-Minute Walk Test in Patients with Rheumatoid Arthritis. Open Journal of Rheumatology and Autoimmune Diseases, 9, 14-24. https://doi.org/10.4236/ojra.2019.91002

Received: December 21, 2018 Accepted: February 24, 2019

Published: February 27, 2019

Copyright $\odot 2019$ by author(s) and Scientific Research Publishing Inc. This work is licensed under the Creative Commons Attribution International License (CC BY 4.0).

http://creativecommons.org/licenses/by/4.0/

\begin{abstract}
Background: The 6-minute walk test (6TC) was initially used as an instrument for assessing physical and cardiorespiratory capacity, but is currently being used to monitor treatments, and compare physical interventions and prognostic evaluation. Although already recognized as a research method in several specialties, 6TC has not been used in rheumatology. Patients with rheumatoid arthritis (RA) may have impaired functional capacity as well as increased cardiovascular mortality. An adequate functional evaluation of these patients is necessary and the 6TC may be useful in this sense. Objective: The aim of this study was to perform the 6-minute walk test in RA patients and to compare the performance with a control group. Method: A cross-sectional study was carried out in which the sample consisted of 85 women, 46 patients with rheumatoid arthritis and 39 healthy controls. A descriptive analysis of the data was performed. One-Way ANOVA methodology was used to compare the patient and control groups followed by the graphic analysis. Results: The distance walked on the 6TC by RA patients was on average 522.2 meters. In the distance control group found in the 6TC was on average 628.8 meters, the difference being statistically significant. Conclusion: In this study the distance covered in 6TC by women with RA was lower than that of healthy women of the same age.
\end{abstract}

\section{Keywords}

6-Minute Walk Test, Rheumatoid Arthritis, Functional Capacity, Physical Capacity, Cardiorespiratory Capacity, Person Performed 


\section{Introduction}

The walk test was originally developed by Cooper as a measure of the level of physical activity of US military soldiers. In the initial model the evaluated person performed the largest race course in 12 minutes [1]. Subsequently, McGavin et al. [2] modified the test using the 12-minute walk instead of running to examine patients with chronic bronchitis. Because it is often exhaustive for sick individuals, a new adaptation of the test to shorter distances was created by creating the 6-minute walk test (6TC). Today, 6TC remains the most commonly used standard for patient assessment and is considered to be a good reproducer of daily activity efforts [3] [4]. Although it was initially used as an instrument for the evaluation of physical and cardiopulmonary capacity, it has been used to monitor several treatments, to compare physical interventions and even to evaluate prognosis [5].

Pulmonology was the first specialty to benefit from the 6-minute walk test information [2]. In patients with respiratory diseases, important data can be obtained for lung capacity measurement. Several studies have compared the information from 6TC with other complementary tests such as spirometry and even laboratory blood gas measurements [6] [7] [8].

In cardiology the benefits of the walk test as a complementary exam are also well documented in the literature. In the SOLVD (Substance of Left Ventricular Dysfunction) study, an important multicenter study in the area, in addition to measurements of the physical and cardiorespiratory capacity provided by the test, the researchers suggested that the parameters of the test can be indicators of mortality and therefore have prognostic value in patients with insufficiency [9]. Another study by Rubim et al. [10] in Brazil also demonstrated that walking test parameters can be indicators of mortality in patients with heart disease. A cohort of 179 patients with the New York Heart Association (NYHA) Functional Classification classes III and IV performed the test followed by echocardiogram and was followed up for 18 months. The authors concluded that the 6TC's worst measures, especially those that covered a distance of less than 500 meters, had a statistically significant relationship with mortality. In addition, there was a good correlation of the 6TC information with echocardiogram data, as already reported in other studies [11] [12].

Although already recognized as an evaluation instrument in several specialties, the 6TC has not been used in rheumatology. In the literature we found few studies in which the test was used to compare interventions, mainly physical exercise, in patients with osteoarthritis and fibromyalgia. To date, we have no information about the usefulness of 6TC in rheumatoid arthritis, which is the object of our study.

The functional capacity of patients diagnosed with RA can be compromised in several aspects, since the manifestations of the disease can decrease joint mobility and range of motion, weaken skeletal muscles and reduce cardiovascular capacity [13]. This may cause a greater level of physical inactivity, and eventually 
compromise activities of daily living, such as bathing, preparing meals, dressing, feeding, as well as walking a certain distance or climbing stairs. On the other hand, restrictions in terms of activity and physical exercise for patients with RA should be increasingly discouraged, as they are mainly related to worsening of joint symptoms, a fact that can contribute to both the inactivity and decline of aerobic capacity, and for increased risk of cardiovascular disease and death. In this sense, in addition to understanding and appropriate management of comorbidities in RA patients, it is fundamental to consider the increase in physical conditioning necessary to attenuate the higher mortality observed in this group [14]. Thus, 6TC can be a practical and extremely useful method for assessing overall, cardiovascular and risk factors of RA patients. In addition to the utilities already reported on the method, it is worth noting that it is an easy-to-perform test, which does not require specific instruments or instruments and therefore of very low cost. Another advantage is that several healthcare professionals can be trained to perform it and obtain valuable data for clinical practice. These characteristics can make the walk test a good tool for use in underdeveloped/ developing countries, especially in centers with difficulties in obtaining complementary exams and more complex tests.

\section{Material and Methods}

A total of 85 women were evaluated, being 46 patients from the Brasília Cohort of rheumatoid arthritis and 39 healthy controls. Brasília Cohort [15]-[21] is an incident cohort of patients diagnosed with RA, followed at the Rheumatology outpatient clinic of the University Hospital of Brasília (HUB), University of Brasília (UnB). RA is defined for inclusion in this cohort as the occurrence of compatible joint symptoms (pain and inflammatory pattern joint edema with or without morning stiffness or other manifestations suggestive of inflammatory joint disease, evaluated by a single observer) lasting more than 6 [22]. All patients selected retrospectively met the EULAR/ACR 2010 criteria [23]. From the time of diagnosis, patients are treated with followed-up prospectively, receiving the standard treatment regimen used in the service, including traditional disease-modifying drugs (DMARDs) or biological response modifiers (biological therapy) as needed. Currently, there are patients who have been followed up for up to 11 years, from the initial diagnosis. The patients were evaluated at the Laboratory of Aptitude and Rheumatology (LAR) of UnB.

The study was carried out in a transversal way, from March to August 2013, with direct interview and review of medical records. The care protocol began with the collection of descriptive clinical data, including the determination of the values of DAS 28 [6], HAQ [7] Visual Analogue Scale (EVA) [8] for pain and fatigue, diagnosis time and presence of comorbidities (hypertension, diabetes mellitus, fibromyalgia, dyslipidemia, hypothyroidism, depression and others). Data on body composition (body mass, height and body mass index-BMI) were collected and the 6TC was performed. 
The 6TC was executed in a HUB corridor with a distance of 40 meters. The materials used were a hand-held timer for the 6-minute marking, a measuring tape for distance measurement and cones for delimiting the start and end points of the course. Each participant was instructed to walk down the aisle and outline the cones at the highest speed during the 6 minutes of the test.

The descriptive analysis of the data was shown by mean, median and standard deviation, in addition to the absolute and relative frequencies and distribution of the total sample in tertiles. One-Way ANOVA methodology was used to compare the groups of patients and controls regarding weight, height, BMI and distance walked in the walking test followed by the graphic analysis. All the hypothesis tests developed in this study considered a significance of $5 \%$, that is, the null hypothesis was rejected when p-value was less than or equal to 0.05 .

The project was submitted to the Human Research Ethics Committee (CEP) of the Faculty of Medicine of UnB (FM-UnB) on June 15, 2007, analyzed and approved on August 22, 2007 (Registration of the project: CEP-FM 028/2007), and all participants signed a free and informed consent form.

\section{Results}

The final sample consisted of 85 female participants, 46 patients with rheumatoid arthritis and 39 healthy controls.

Exclusion criteria were defined as difficulties or impediment to perform the 6TC, such as severe osteoarticular disorders in the lower limbs, blood pressure above 140/100 mmHg or cardiac dysfunction. The group of patients had a mean age of 49 years, and 6.5 years of diagnosis of the disease. The control group had a mean age of 37.43 years. The descriptive analysis of the sample can be visualized in Table 1.

Regarding body composition, it was noted that the majority of the patients, approximately $65 \%$, were overweight, according to the classification of the World Health Organization [24]. The amount and distribution of body fat appear to be concentrated in the central region of the body, according to the analysis of the percentage of body fat and BMI, which showed, respectively, that the majority of the sample has high body fat and high or high risk high risk of developing heart disease.

The evaluation of the specific control parameters of the disease, its signs, symptoms and associated comorbidities presented important data. When the DAS 28 scores were analyzed, the sample was most often classified as low disease activity or remission. In addition, a similar satisfactory behavior was also shown in the HAQ values, which indicated that $84 \%$ of this sample had no, little or moderate difficulty performing basic life tasks. The levels of pain and fatigue appear to be well controlled and, finally, fibromyalgia and arterial hypertension were the most frequent comorbidities in this sample.

The distance walked on the 6TC by patients with RA ranged from 347 to $675 \mathrm{~m}$, with an overall mean of $522.4 \pm 76.8 \mathrm{~m}$. The distribution of the data was classified as lower limit $(\leq 507 \mathrm{~m})$, intermediate zone $(<507 \mathrm{~m} \geq 565 \mathrm{~m})$ and upper 
Table 1. Descriptive analysis of the sample.

\begin{tabular}{|c|c|c|c|}
\hline Variable & Mean \pm Standard deviation & Median & n (\%) \\
\hline AGE (years) & $49 \pm 14.95$ & 49 & \\
\hline DIAGNOSTIC TIME & $6.5 \pm 3.28$ & 7 & \\
\hline DAS 28 & $3.04 \pm 1.44$ & 2.83 & \\
\hline Remission & & & $26(48.1)$ \\
\hline Low activity & & & $6(11.1)$ \\
\hline Moderate activity & & & $17(31.5)$ \\
\hline High activity & & & $5(9.3)$ \\
\hline HAQ & $0.593 \pm 0.63$ & 0.375 & \\
\hline Little or no difficulty & & & $17(30.4)$ \\
\hline Difficulty moderate & & & $30(53.6)$ \\
\hline Much difficulty & & & $6(10.7)$ \\
\hline Impossible to perform & & & $3(5.3)$ \\
\hline $\operatorname{BMI}\left(\mathrm{kg} / \mathrm{m}^{2}\right)$ & $26.60 \pm 5.31$ & 25.59 & \\
\hline Under weight & & & $2(3.3)$ \\
\hline Ideal weight & & & $28(45.0)$ \\
\hline Overweight & & & $19(31.1)$ \\
\hline Obesity Grade 1 & & & $10(16.4)$ \\
\hline Obesity Grade 2 & & & $1(1.6)$ \\
\hline Obesity Grade 3 & & & $1(1.6)$ \\
\hline Fat mass (\%) & $35.48 \pm 6.83$ & 35.34 & \\
\hline Great & & & $1(2.8)$ \\
\hline Good & & & $3(8.3)$ \\
\hline Above average & & & $2(5.6)$ \\
\hline Average & & & $2(5.6)$ \\
\hline Below average & & & $7(19.4)$ \\
\hline $\mathrm{Bad}$ & & & $5(13.9)$ \\
\hline Too bad & & & $16(44.4)$ \\
\hline \multicolumn{4}{|l|}{ Pain visual analog scale (mm) } \\
\hline $0-34$ & & & $20(48.8)$ \\
\hline $35-66$ & & & $14(34.1)$ \\
\hline $67-100$ & & & $7(17.1)$ \\
\hline \multicolumn{4}{|l|}{$\begin{array}{l}\text { Visual analogue scale fatigue } \\
\qquad(\mathrm{mm})\end{array}$} \\
\hline $0-34$ & & & $23(57.5)$ \\
\hline $35-66$ & & & $9(22.5)$ \\
\hline $67-100$ & & & $8(20)$ \\
\hline \multicolumn{4}{|l|}{ Comorbities } \\
\hline Fibromyalgia & & & $20(42.6)$ \\
\hline Systemic arterial hypertension & & & $15(31.9)$ \\
\hline Dyslipidemia & & & $10(21.3)$ \\
\hline Hypothyroidism & & & $8(17.0)$ \\
\hline Diabetes & & & $6(12.8)$ \\
\hline Depression & & & $10(21.3)$ \\
\hline Others & & & $10(21.3)$ \\
\hline
\end{tabular}


limit $(>565 \mathrm{~m}) .34 .1 \%$ of the patients were in the first tertile, $34.1 \%$ in the intermediate tertile and $31.8 \%$ in the last tertile. 14 patients $(35.9 \%)$ walked a distance of less than 500 meters. In the distance control group found in the 6TC ranged from 521 to 746 meters. The comparison between the two groups can be seen in Table 2.

\section{Discussion}

This study aimed to verify the functional capacity of female patients of Brasília Cohort of RA through the 6TC, in addition to demonstrating the distribution of performance in tertiles and comparing it with a control group. The values presented in the 6TC tertiles demonstrate that the physical performance of the majority of RA patients was below that of healthy women of similar age, according to the study by Enright and Sherrill [25]. Although there is currently no in the scientific literature a normative of this specific test for the RA public, the result was compatible with that of the elderly from 60 to 65 years [26]. When compared to the control group, the group of patients with rheumatoid arthritis presented inferior performance, being this variable with statistically significant difference.

BMI and fat percentage were high and this behavior is common in patients with RA [27] [28]. In addition, what attracted attention was the fact that they had a higher amount of body fat in the region of the trunk, alerting to the high cardiovascular risk [29] [30] [31].

The risk of morbidity and mortality from cardiovascular diseases in patients with RA is high [32] such that the evaluation of functional and cardiovascular capacity is becoming an increasingly frequent recommendation [33]. In addition, this is justified because of the ease of execution of the 6TC, especially when the care is performed by a multi and interdisciplinary team and due to the practical application regarding the referral of the patient, first, to the cardiologist to verify the cardiological status and, later to the physiotherapist and physical education teachers for rehabilitation and development of cardiovascular fitness.

This indication is especially advisable in cases of poor performance on the 6TC, high frequency of associated diseases, worse status of body composition and worse classifications of DAS 28 and HAQ. However, we can not rule out the fact that, in general, independent of the results found in the 6TC, the diagnosis of RA per se is enough to indicate the practice of physical activity [34] to intervene as an adjuvant in the treatment of RA and its more frequent comorbidities such as hypertension, fibromyalgia, dyslipidemias, obesity, depression, diabetes and others [35] [36] [37] [38] [39].

In addition, the experience of this work brings to light a warning to health professionals, since the similarity in terms of cardiovascular and functional condition of individuals with different levels of control of RA, once again, shows the need for referral and indication of the practice of physical activities for individuals with RA, even though it was diagnosed early in the disease and well controlled over time. 
Table 2. Mean and standard deviation of weight, height, body mass index and walk by group (RA and control) followed by F, p-value and R2 of ANOVA.

\begin{tabular}{|c|c|c|c|c|c|c|c|}
\hline \multirow{3}{*}{ Variable } & \multicolumn{4}{|c|}{ Group } & \multicolumn{3}{|c|}{ ANOVA One Way } \\
\hline & \multicolumn{2}{|c|}{ Control } & \multicolumn{2}{|c|}{ RA } & \multirow[b]{2}{*}{$\mathrm{F}$} & \multirow[b]{2}{*}{$\mathrm{p}$-value } & \multirow[b]{2}{*}{$\mathrm{R}^{2}$} \\
\hline & Mean & $\begin{array}{l}\text { Standard } \\
\text { deviation }\end{array}$ & Mean & $\begin{array}{l}\text { Standard } \\
\text { deviation }\end{array}$ & & & \\
\hline Weight & 61.1 & 8.6 & 65.9 & 13.9 & 3.5 & 0.0649 & 0.040 \\
\hline Height & 1.60 & 0.06 & 1.58 & 0.05 & 2.9 & 0.0911 & 0.034 \\
\hline BMI & 23.8 & 3.1 & 26.4 & 4.7 & 8.3 & 0.0050 & 0.090 \\
\hline Walking & 628.8 & 52.1 & 525.2 & 73.7 & 54.4 & $<0001$ & 0.393 \\
\hline
\end{tabular}

The reduced CCV and functional in individuals with RA also appears to be characteristic of other rheumatologic and autoimmune diseases such as systemic lupus erythematosus (SLE) [40] [41] and fibromyalgia [42], when compared to individuals of the same genus and age [25] or the elderly [26].

It should be borne in mind that this study presents some limitations in the extrapolation of the conclusions, such as the fact that the study is transversal (not determining cause and effect relationship), limited $\mathrm{N}$, variability of patient age and controls, the time of diagnosis and the treatments used. Further studies in the area should be performed to confirm these results.

\section{Conclusion}

Thus, it was concluded that the distance covered by women with RA is lower than that traveled by healthy women of the same age. Finally, the pioneerism of the proposal stands out, since no references were found from other research groups investigating the results of 6TC tests in individuals with RA. It is important that, in the future, cohort studies are developed that assess the behavior of functional capacity over time in comparison with healthy individuals.

\section{Acknowledgements}

We thank the team of Rheumatology of the Hospital Universitário de Brasília (Hub-UnB)

\section{Conflicts of Interest}

The authors have no competing interests to this article to disclose.

\section{References}

[1] Cooper, K.H. (1968) A Means of Assessing Maximal Oxygen Intake. Correlation between Field and Treadmill Testing. JAMA, 203, 201-204.

https://doi.org/10.1001/jama.1968.03140030033008

[2] McGavin, C.R., Artvinli, M., Naoe, H. and McHardy, G.J. (1978) Dyspnoea, Disability, and Distance Walked: Comparison of Estimates of Exercise Performance in Respiratory Disease. The BMJ, 2, 241-243. https://doi.org/10.1136/bmj.2.6132.241 
[3] Butland, R.J., Pang, J., Gross, E.R., Woodcock, A.A. and Geddes, D.M. (1982) Two-, Six-, and 12-Minute Walking Tests in Respiratory Disease. The BMJ (Clinical Research Ed.), 284, 1607-1608. https://doi.org/10.1136/bmj.284.6329.1607

[4] Solway, S., Brooks, D., Lacasse, Y. and Thomas, S. (2001) A Qualitative Systematic Overview of the Measurement Properties of Functional Walk Tests Used in the Cardiorespiratory Domain. Chest, 119, 256-270.

https://doi.org/10.1378/chest.119.1.256

[5] ATS Committee on Proficiency Standards for Clinical Pulmonary Function Laboratories (2002) ATS Statement: Guidelines for the Six-Minute Walk Test. American Journal of Respiratory and Critical Care Medicine, 166, 111-117. https://doi.org/10.1164/ajrccm.166.1.at1102

[6] Morales-Blanhir, J.E., Palafox Vidal, C.D., Rosas Romero, M.J., Garcia Castro, M.M., Londono Villegas, A. and Zamboni, M. (2011) Six-Minute Walk Test: A Valuable Tool for Assessing Pulmonary Impairment. Jornal Brasileiro de Pneumologia, 37, 110-117. https://doi.org/10.1590/S1806-37132011000100016

[7] Miyamoto, S., Nagaya, N., Satoh, T., Kyotani, S., Sakamaki, F., Fujita, M., et al. (2000) Clinical Correlates and Prognostic Significance of Six-Minute Walk Test in Patients with Primary Pulmonary Hypertension. Comparison with Cardiopulmonary Exercise Testing. American Journal of Respiratory and Critical Care Medicine, 161, 487-492. https://doi.org/10.1164/ajrccm.161.2.9906015

[8] Montes de Oca, M., Ortega Balza, M., Lezama, J. and Lopez, J.M. (2001) Chronic Obstructive Pulmonary Disease: Evaluation of Exercise Tolerance Using Three Different Exercise Tests. Archivos de Bronconeumología, 37, 69-74. https://doi.org/10.1016/S0300-2896(01)75017-X

[9] Bittner, V., Weiner, D.H., Yusuf, S., Rogers, W.J., McIntyre, K.M., Bangdiwala, S.I., et al. (1993) Prediction of Mortality and Morbidity with a 6-Minute Walk Test in Patients with Left Ventricular Dysfunction. SOLVD Investigators. JAMA, 270, 1702-1707. https://doi.org/10.1001/jama.1993.03510140062030

[10] Rubim, V.S.M., Drumond Neto, C., Romeo, J.L.M. and Montera, M.W. (2006) Prognostic Value of the Six-Minute Walk Test in Heart Failure. Arquivos Brasileiros de Cardiologia, 86, 120-125.

[11] Rostagno, C., Olivo, G., Comeglio, M., Boddi, V., Banchelli, M., Galanti, G., et al. (2003) Prognostic Value of 6-Minute Walk Corridor Test in Patients with Mild to Moderate Heart Failure: Comparison with Other Methods of Functional Evaluation. European Journal of Heart Failure, 5, 247-252. https://doi.org/10.1016/S1388-9842(02)00244-1

[12] Zugck, C., Kruger, C., Durr, S., Gerber, S.H., Haunstetter, A., Hornig, K., et al. (2000) Is the 6-Minute Walk Test a Reliable Substitute for Peak Oxygen Uptake in Patients with Dilated Cardiomyopathy? European Heart Journal, 21, 540-549. https://doi.org/10.1053/euhj.1999.1861

[13] Hsieh, L.F., Chen, S.C., Chuang, C.C., Chai, H.M., Chen, W.S. and He, Y.C. (2009) Supervised Aerobic Exercise Is More Effective than Home Aerobic Exercise in Female Chinese Patients with Rheumatoid Arthritis. Journal of Rehabilitation Medicine, 41, 332-337. https://doi.org/10.2340/16501977-0330

[14] Pereira, I.A., Mota, L.M., Cruz, B.A., Brenol, C.V., Fronza, L.S., Bertolo, M.B., et al. (2012) 2012 Brazilian Society of Rheumatology Consensus on the Management of Comorbidities in Patients with Rheumatoid Arthritis. Revista Brasileira de Reumatologia, 52, 474-495.

[15] da Mota, L.M., Santos Neto, L.L., Pereira, I.A., Burlingame, R., Menard, H.A. and 
Laurindo, I.M. (2011) Autoantibodies in Early Rheumatoid Arthritis: Brasilia Cohort: Results of a Three-Year Serial Analysis. Revista Brasileira de Reumatologia, 51, 564-571. https://doi.org/10.1590/S0482-50042011000600004

[16] Da Mota, L.M., dos Santos Neto, L.L., Burlingame, R., Menard, H.A. and Laurindo, I.M. (2010) Laboratory Characteristics of a Cohort of Patients with Early Rheumatoid Arthritis. Revista Brasileira de Reumatologia, 50, 375-388. https://doi.org/10.1590/S0482-50042010000400004

[17] Da Mota, L.M., Laurindo, I.M. and dos Santos Neto, L.L. (2010) Prospective Evaluation of the Quality of Life in a Cohort of Patients with Early Rheumatoid Arthritis. Revista Brasileira de Reumatologia, 50, 249-261. https://doi.org/10.1590/S0482-50042010000300005

[18] Da Mota, L.M., Laurindo, I.M. and dos Santos Neto, L.L. (2010) Demographic and Clinical Characteristics of a Cohort of Patients with Early Rheumatoid Arthritis. Revista Brasileira de Reumatologia, 50, 235-248. https://doi.org/10.1590/S0482-50042010000300004

[19] Silva, C.R., Costa, T.F., de Oliveira, T.T., Muniz, L.F. and da Mota, L.M. (2013) Physical Activity among Patients from the Brasilia Cohort of Early Rheumatoid Arthritis. Revista Brasileira de Reumatologia, 53, 394-399. https://doi.org/10.1590/S0482-50042013000500005

[20] Ferreira, C.C., da Mota, L.M., Oliveira, A.C., de Carvalho, J.F., Lima, R.A., Simaan, C.K., et al. (2013) Frequency of Sexual Dysfunction in Women with Rheumatic Diseases. Revista Brasileira de Reumatologia, 53, 35-46.

[21] Da Mota, L.M., Dos Santos Neto, L.L., Oliveira, A.C., Pereira, I.A., Burlingame, R.W., Menard, H.A., et al. (2012) Baseline HAQ and SF-36 Questionnaire Scores Cannot Predict Clinical Remission, Radiographic Progression or the Need for Biological Therapy in a Three-Year Prospective Study of a Brazilian Early Rheumatoid Arthritis Cohort. Rheumatology International, 32, 3937-3943.

https://doi.org/10.1007/s00296-011-2261-8

[22] Arnett, F.C., Edworthy, S.M., Bloch, D.A., McShane, D.J., Fries, J.F., Cooper, N.S., et al. (1988) The American Rheumatism Association 1987 Revised Criteria for the Classification of Rheumatoid Arthritis. Arthritis \& Rheumatology, 31, 315-324. https://doi.org/10.1002/art.1780310302

[23] Aletaha, D., Neogi, T., Silman, A.J., Funovits, J., Felson, D.T., Bingham, C.O., et al. (2010) 2010 Rheumatoid Arthritis Classification Criteria: An American College of Rheumatology/European League against Rheumatism Collaborative Initiative. Annals of the Rheumatic Diseases, 69, 1580-1588. https://doi.org/10.1136/ard.2010.138461

[24] Santana, F.S., Cunha Nascimento, D., Freitas, J.P.M., Miranda, R.F., Muniz, L.F., Santos Neto, L., et al. (2014) Avaliação da capacidade funcional em pacientes com artrite reumatoide: Implicações para a recomendação de exercícios físicos. Revista Brasileira de Reumatologia, 54, 378-385. https://doi.org/10.1016/j.rbr.2014.03.021

[25] Enright, P.L. and Sherrill, D.L. (1998) Reference Equations for the Six-Minute Walk in Healthy Adults. American Journal of Respiratory and Critical Care, 158, 1384-1387. https://doi.org/10.1164/ajrccm.158.5.9710086

[26] Jones, C.J. and Rikli, R.E. (2002) Measuring Functional Fitness of Older Adults. The Journal on Active Aging, 1, 24-30.

[27] Dao, H.H., Do, Q.T. and Sakamoto, J. (2011) Abnormal Body Composition Phenotypes in Vietnamese Women with Early Rheumatoid Arthritis. Rheumatology, 50, 1250-1258. https://doi.org/10.1093/rheumatology/ker004 
[28] Book, C., Karlsson, M.K., Akesson, K. and Jacobsson, L.T. (2009) Early Rheumatoid Arthritis and Body Composition. Rheumatology, 48, 1128-1132. https://doi.org/10.1093/rheumatology/kep165

[29] Gharipour, M., Sarrafzadegan, N., Sadeghi, M., Andalib, E., Talaie, M., Shafie, D., et al. (2013) Predictors of Metabolic Syndrome in the Iranian Population: Waist Circumference, Body Mass Index, or Waist to Hip Ratio? Cholesterol, 2013, Article ID: 198384. https://doi.org/10.1155/2013/198384

[30] Ghazali, S.M. and Sanusi, R.A. (2010) Waist Circumference, Waist to Hip Ratio, and Body Mass Index in the Diagnosis of Metabolic Syndrome in Nigerian Subjects. Nigerian Journal of Physiological Sciences, 25, 187-195.

[31] Wang, F., Wu, S., Song, Y., Tang, X., Marshall, R., Liang, M., et al. (2009) Waist Circumference, Body Mass Index and Waist to Hip Ratio for Prediction of the Metabolic Syndrome in Chinese. Nutrition, Metabolism \& Cardiovascular Diseases, 19, 542-547. https://doi.org/10.1016/j.numecd.2008.11.006

[32] Gonzalez, A., Maradit Kremers, H., Crowson, C.S., Nicola, P.J., Davis, J.M., Therneau, T.M., et al. (2007) The Widening Mortality Gap between Rheumatoid Arthritis Patients and the General Population. Arthritis \& Rheumatology, 56, 3583-3587. https://doi.org/10.1002/art.22979

[33] De Jong, Z., Munneke, M., Zwinderman, A.H., Kroon, H.M., Jansen, A., Ronday, K.H., et al. (2003) Is a Long-Term High-Intensity Exercise Program Effective and Safe in Patients with Rheumatoid Arthritis? Results of a Randomized Controlled Trial. Arthritis \& Rheumatology, 48, 2415-2424. https://doi.org/10.1002/art.11216

[34] Baillet, A., Vaillant, M., Guinot, M., Juvin, R. and Gaudin, P. (2012) Efficacy of Resistance Exercises in Rheumatoid Arthritis: Meta-Analysis of Randomized Controlled Trials. Rheumatology (Oxford), 51, 519-527.

https://doi.org/10.1093/rheumatology/ker330

[35] Ruiz, J.R., Sui, X., Lobelo, F., Morrow, J.R., Jackson, A.W., Sjostrom, M., et al. (2008) Association between Muscular Strength and Mortality in Men: Prospective Cohort Study. BMJ, 337, a439. https://doi.org/10.1136/bmj.a439

[36] Gale, C.R., Martyn, C.N., Cooper, C. and Sayer, A.A. (2007) Grip Strength, Body Composition, and Mortality. International Journal of Epidemiology, 36, 228-235. https://doi.org/10.1093/ije/dyl224

[37] LaMonte, M.J., Barlow, C.E., Jurca, R., Kampert, J.B., Church, T.S. and Blair, S.N. (2005) Cardiorespiratory Fitness Is Inversely Associated with the Incidence of Metabolic Syndrome: A Prospective Study of Men and Women. Circulation, 112, 505-512. https://doi.org/10.1161/CIRCULATIONAHA.104.503805

[38] Jurca, R., Lamonte, M.J., Barlow, C.E., Kampert, J.B., Church, T.S. and Blair, S.N. (2005) Association of Muscular Strength with Incidence of Metabolic Syndrome in Men. Medicine and Science in Sports and Exercise, 37, 1849-1855. https://doi.org/10.1249/01.mss.0000175865.17614.74

[39] Jurca, R. and LaMonte, M.J. (2005) Fitness and Physical Activity as Predictors of Mortality in Unhealthy Men. Clinical Journal of Sport Medicine, 15, 462-463. https://doi.org/10.1097/01.jsm.0000188046.83674.c3

[40] Balsamo, S., da Mota, L.M., de Carvalho, J.F., Nascimento, D.C., Tibana, R.A., de Santana, F.S., et al. (2013) Low Dynamic Muscle Strength and Its Associations with Fatigue, Functional Performance, and Quality of Life in Premenopausal Patients with Systemic Lupus Erythematosus and Low Disease Activity: A Case-Control Study. BMC Musculoskeletal Disorders, 14, 263.

https://doi.org/10.1186/1471-2474-14-263 
[41] Balsamo, S., Nascimento, D.C., Tibana, R.A., Santana, F.S., da Mota, L.M.H. and Santos-Neto, L.L. (2013) The Quality of Life of Patients with Lupus Erythematosus Influences Cardiovascular Capacity in 6-Minute Walk Test. Revista Brasileira de Reumatologia, 53, 75-87.

[42] Cardoso, F.S., Curtolo, M., Natour, J. and Lombardi Júnior, I. (2011) Avaliação da qualidade de vida, força muscular e capacidade funcional em mulheres com fibromialgia. Revista Brasileira de Reumatologia, 51, 344-350.

https://doi.org/10.1590/S0482-50042011000400006 